\title{
Meta-Research: How problematic citing practices distort science
}

\author{
Serge P.J.M. Horbach ${ }^{* 1,2}$, Kaare Aagaard, Jesper W. Schneider \\ ${ }^{1}$ Aarhus University, Department of Political Sciences, Danish Centre for Studies in Research and \\ Research Policy, Bartholins Allé 7, 8000 Aarhus C, Denmark \\ ${ }^{2}$ Centre for Science and Technology Studies (CWTS), Faculty of Social Sciences, Leiden University, \\ Wassenaarseweg 62A, 2333 AL Leiden, The Netherlands \\ *Corresponding author \\ s.horbach@ps.au.dk \\ $+4587166245$ \\ ORCID: 0000-0003-0406-6261
}

Kaare Aagaard: ORCID: 0000-0003-2983-073X

Jesper W. Schneider: ORCID: 0000-0001-5556-0919

\begin{abstract}
Citing practices constitute a core element in scientific research and communication in which they serve several important functions. They both comprise the principal unit of science's social reward system and they establish epistemic genealogy, showing the foundations on which claims are built. Distorted or problematic citing behaviour can hence have major harmful consequences for the wellfunctioning of the scientific enterprise.

In this article we employ a case study approach to show how, even in the field of research integrity, or more broadly, meta-research, researchers commonly adhere to suboptimal citing practices. Our findings highlight, among other shortcomings, an apparent lack of critical engagement with the cited literature, leading to incorrect reproductions of claims and overgeneralisation of supposed research findings. We link such problematic citing practices to the state of crisis that science is currently claimed to face, discussing how these practices might be both a symptom and a cause of these crises.
\end{abstract}

\section{Keywords}

Citing practices; Questionable Research Practices; Scholarly publishing; bibliometrics; Scholarly literature

\section{Acknowledgement}

This work is supported by the PRINT project (Practices, Perceptions, and Patterns of Research Integrity) funded by the Danish Agency for Higher Education and Science (Danish Ministry of Higher Education and Science) under grant No 6183-00001B. 


\section{Background}

Over the past years, alarms have been raised about the well-functioning of the scientific enterprise. Scandals involving prominent scientists engaging in fraudulent behaviour (e.g., Callaway, 2011), the widely publicized failures to reproduce landmark studies in several disciplines (e.g., OSF, 2015; Prinz, Schlange, \& Asadullah, 2011), and worries about the consequences of the apparently high pressure on researchers to publish quickly and in large quantities (e.g., Edwards \& Roy, 2016), to name just a few concerns, have triggered debates within the scientific community and well beyond. In particular these concerns have addressed the social organisation of the science system, the epistemic validity of scientific claims, as well as the system's trustworthiness within the wider society (Vazire, 2017). Several prominent stakeholders have consequently announced science to be in a state of crisis - be it either a 'reproducibility crisis', 'theory crisis', 'crisis of trust' or any other variant (among many others: Bird, 2018; Coleman, 2021; Saltelli \& Funtowicz, 2017; Wilson, 2020).

Several causes of this purported crisis have been proposed. Prominently among them are the simplistic and one-dimensional way of assessing researchers, commonly based on publication and citation counts (Aksnes, Langfeldt, \& Wouters, 2019; de Rijcke, Wouters, Rushforth, Franssen, \& Hammarfelt, 2015); the use of a set of so-called questionable research practices (QRPs) to obtain or report desired results; poor experimental set-up and methodology (Wicherts, 2017); and a lack of proper theorising or building on previous literature (Oberauer \& Lewandowsky, 2019). While being listed as causes, some of these may in fact rather be symptoms or consequences of the science's ongoing crisis. Either way, researchers' citing practices play a prominent role in several of these phenomena. However, citation practices have only rarely been the focus of studies relating to the integrity or validity of science (with some exceptions, including (Bordignon, 2020; Greenberg, 2009b; G. Leng \& Leng, 2020b; Martin, 2013)).

Citing practices constitute a core element in scientific research and serve several important functions (Grafton, 1997). Most notably, references and citations comprise the essential units that as 'footprints' allow us to follow the progress of science (Cozzens, 1985). Another derivative of citing is the 'image boosting' of cited authors created by accumulated citations, whereby citations become indicators of scientific endeavour. (Camacho-Miñano \& Núñez-Nickel, 2009). Citing practices are accordingly fundamental in science's internal reward system, 'giving credit where credit is due', and in the epistemological genealogy of scientific claims, showing the foundations on which claims are built. Citing practices also determine Journal Impact Factors and thus play a crucial role for the prestige and stratification of publication outlets. In these respects, the act of citing is at the same time part of the broader concept of research behaviour, which has both cognitive and social dimensions (e.g., Anderson, Ronning, De Vries, \& Martinson, 2010; Cozzens, 1989; Cronin, 2005; Gilbert, 1977; Teplitskiy, Duede, Menietti, \& R., 2020, 31 Aug ). These practices can be seen as customary activities, sometimes socially determined and/or socially sanctioned.

Citations hence play a strong social as well as an epistemological role in the organisation and selfregulation of (academic) research. While they have been a principal object of research within the field of bibliometrics for a century (Gross \& Gross, 1927), their role in the current crisis debates in science has been largely overlooked (apart from some exceptions, including the ones mentioned above). In addition, the social and epistemological dimensions of citing practices have traditionally been separated and seldom studied in conjunction.

Even though trends are shifting, research evaluation still relies heavily on either direct or indirect citation counts, the latter for instance through the use of h-indices (Hirsch, 2005) or Journal Impact Factors (Eugene Garfield, 1955). But not only do scientists' rewards, promotions, and research funds 
depend on the number of times their papers are cited (and by whom and in which journals), at the same time, the global analysis of citations is also a general tool for evaluating and managing science at organisational and national levels (Aksnes, 2006, p. 177). In addition, citing practices inform readers about past literatures and constitute a framework to establish hypotheses, subsequently used in null-hypothesis significance tests that form the core knowledge production model in many disciplines (Hubbard, 2016). They also comprise a prime sampling strategy for including articles in (systematic) literature reviews (Bishop, 2019), which are particularly common in medical research to compile evidence from multiple studies. Correct and responsible citing practices are therefore essential to maintain the well-functioning of the scientific enterprise. We argue however, that there are strong indications that problematic citing practices are widespread and that jeopardize both of the essential functions of references and citations mentioned above. As such, we make the argument that these problematic citing practices both constitute a particularly detrimental QRP in and of itself, as well as one of the major causes triggering a wider set of other QRPs.

In this article we take a reflective stance by presenting the results of a case study into citing behaviour within the research area of research integrity and questionable research practices. Using references to a highly cited landmark study in this discipline (John, Loewenstein, \& Prelec, 2012), we analyse how researchers in this field of study, who are expected to be well-aware of the potentially distorting effects of problematic citing behaviour, engage with the literature. Through qualitative coding of the citing contexts of 300 citing articles, we analyse both whether claims in the cited study are correctly reproduced and whether the citing authors critically engage with the cited article. For both, we find concerning results. After giving an elaborate overview of the literature on citation behaviour, this manuscript outlines the methodology of our case study. It then presents empirical results, which it relates back to the previous literature in section 5 .

\section{Citing practices}

The processes of writing and citing are integral to research (Popper, 1945). Knowledge claims are put forward in texts, but if no one reads and uses them, such claims will not contribute to progress of science and the researchers behind them risk being isolated (Luukkonen, 1997). However, in much of the meta-research literature, the importance of these practices tends to be neglected. For example Munafò and colleagues (2017) outline six phases in their attempt to link certain QRPs to the research process: (1) generate and specify hypothesis, (2) design study, (3) collect data and conduct study, (4) analyse data and test hypothesis, (5) interpret results and (6) publish and/or conduct new experiments. Neglecting the integral writing and citing processes and thereby also the important QRPs linked to selective reporting and citing (Bouter, Tijdink, Axelsen, Martinson, \& ter Riet, 2016), is debatable.

Writing, including decisions about what to report and how to report it, what to cite and how to represent it, are by necessity normative, selective and persuasive activities. However, 'persuasive' can turn into 'biased' or even 'distortive' activities (Chambers, 2017; O'Boyle, Banks, \& GonzalezMulé, 2017). Presumably widespread use of selective reporting in some fields (Banks et al., 2016; John et al., 2012; van der Steen et al., 2018), excessive numbers of published "positive" empirical findings (Fanelli, 2010), and low replication rates can be seen as consequences of this (e.g., OSF, 2015), and testify that this balancing act is difficult. Accordingly, writing and citing practices can be questionable, fraudulent and damaging to the research enterprise, something Munafò and colleagues (2017) fail to illustrate.

\subsection{The paradoxes of citing}


References given in a text serve multiple functions; they are part of a rhetorical (conceptual, cognitive) system through which scientists try to persuade each other of their knowledge claims. Citations, on the other hand, are derived from individually cited references and are considered to be different constructs (De Solla Price 1970). They are part of a reward (recognition, reputation) system through which credit for achievements are allocated. While analytically distinct, the two systems are concretely indistinguishable, they are both present as impetus and constraint in any given act of citing (Cozzens, 1989).

Citing is surrounded by a number of paradoxes. The main paradox is that while researchers seem to accept the need for some rules or normative practices, when asked, their actual citing practices often seem to deviate from such ideals (Nicolaisen, 2007). Most would probably agree that responsible citing practice is both vital and necessary for the complex system of scientific communication to function properly. That is, documenting the flow of ideas and warranting their validity and reliability (Cronin, 2005, 2016). The only way to observe the progress of science is by knowing the original sources of ideas and how they subsequently evolved (de Solla Price 1963; Eugene Garfield, 1955). Researchers would probably also agree that citing is necessary for acknowledging "intellectual debts" in relation to the cited work. In the most extreme, but also the most obvious case, copying a piece of text from another source without proper quotation corresponds to plagiarism. However, from there on, it is less clear-cut how one is expected to pay homage to "intellectual debts".

Subscribing to such views is in line with a normative position that sees citing as the reaffirmation of the underlying norms of scientific behaviour (Anderson, 2000; Anderson et al., 2010; Kaplan, 1965; R. K. Merton, 1942). Such norms oblige researchers to cite the work upon which they draw and in this way credit contributions by others (R. Merton, 1979). References are therefore seen as an institutionalized way of allocating recognition and reward. It is furthermore assumed that citations take on their own meaning as counts go up. Here they are perceived as powerful constructs that may establish beliefs. They give published statements visibility and credibility, and they signal their 'perceived worth', 'quality', 'significance', 'importance', 'influence' or 'impact', not only to the cited work, but also to its authors, their institutions, and the journals in which they are published. Hereby citations become closely linked to stratification, recognition and the use of performance indicators (Hagstrom, 1965; Kaplan, 1965; R. Merton, 1979). Latour and Woolgar (1986) discuss a representation of the research process in which writing and citing practices play a crucial role. In their 'credibility cycle', Latour and Woolgar see credibility as being manifested and measurable in six ways: staffing, data, arguments, publications, peer recognition, and money. Citing practices play a major role in the stages of argumentation, publication and peer recognition, thereby constituting an important mechanism in establishing and maintaining credibility and authority.

Some empirical evidence suggests that researchers' motivations to cite, in general, are based on the 'perceived worth' of cited work, its topical and cognitive relevance and novelty. While this is in line with the norm of acknowledging 'intellectual debts', it is important to note that this evidence mainly is restricted to studies among astrophysicists (Baldi, 1998; Kurtz et al., 2005).

Many other studies have documented that citing practices vary considerably across fields (Hargens, 2000) influenced by several cognitive and social standards within these fields. Numerous inconsistencies have been documented, most notably in a series of articles by MacRoberts and MacRoberts (1984; 1989a, 1989b; 2010; 2017; 1986). Others have studied biased citing, where some works, e.g. a measure or a method, are cited essentially every time they are used, while others are never cited even though they may be used equally often (E. Garfield, 1975; Robert K. Merton, 1968). They also describe claims that re-citing without reading is common (Simkin \& Roychowdhury, 2006); 
that authors cite works that are already frequently cited (R. K. Merton, 1968; Robert K. Merton, 1988); that authors cite papers in high-impact journals more often than papers in low-impact journals (e.g., Callaham, Wears, \& Weber, 2002; van Dalen \& Henkens, 2005); that authors cite works they are familiar with, and recite them over time (e.g., Johnson \& Oppenheim, 2007; Wallace, Lariviere, \& Gingras, 2012); that authors cite the first study that reports a particular finding, even when later studies are more appropriate (J. A. loannidis, 2005); (for an overview, see e.g. Bornmann and Daniel (2008)).

Such deviations from the perceived norms of citing are picked up in antagonistic social constructivist positions which challenge normative views on citing practices (Gilbert, 1977; Latour, 1987; Latour \& Woolgar, 1986). Gilbert (1977) argues that researchers mainly cite publications for rhetorical and strategic reasons, that is, reasons that do not, or only scarcely, depend on the "perceived worth" of the cited work. To persuade the scientific community of the value and importance of their own publication, authors, according to this perspective, instead use references as rhetorical tools. Seen from this perspective, references vary in their power of persuasion, not necessarily according to epistemic factors, but also due to social factors: e.g., who authored the work or where it was published. It is perceived as more persuasive to cite an authoritative work, and authors accordingly tend to select references that will be regarded as authoritative by the intended audience. It naturally follows that such positions dismiss the use of citations as performance measures entirely. Similarly, we also have evidence from both general and domain specific studies suggesting that motivations for citing have more to do with whom one knows rather than what one knows. For example, Teplitskiy and colleagues (2020, 31 Aug ) recently claimed that article status more than epistemic claims is what drives decisions to cite. Notice, according to White (2004), persuasion comes in two kinds, "persuasion by namedropping" and "persuasion by distortion". The former refers to selective and disproportionate citing of works by established authorities, so as to gain credibility by association. The latter refers to misrepresentation of cited works in citing contexts, for example twisting claims to one's own benefit, 'window dressing' where critical claims are disregarded while a reference is still given 'to bestow credit', or simply re-citing what others cite about a work without reading it.

\subsection{The function of references}

As indicated above, multiple studies have demonstrated convincingly that references serve a multitude of functions and that citing is a complex practice. In a review of previous studies, Small (1982) identified five functional categories of a cited reference. It may be: 1) refuted, 2) noted only, 3) reviewed, 4) applied, or 5) supported by the citing work. Subsequently, these categories were characterized as 1) negative, 2) perfunctory, 3) compared, 4) used and 5) substantiated. Notably, the distribution of references over these categories suggested that between one third and half of all references given in a paper could be considered nonessential (or perfunctory) to the given context (Chubin \& Moitra, 1975; Moravcsik \& Murugesan, 1975). Often, the density and type of references given tends to follow the publication format. For example, most empirical articles are structured as a progression from the general to the particular (Law, 1986). The introduction motivates the study and situates it in the broader literature. Consequently, the bulk of references is typically given in the introduction section and many of these are cited in a perfunctory manner (Moravcsik \& Murugesan, 1975). Notably, many highly cited publications receive their citations from references given in this perfunctory manner in introduction sections (Voos \& Dagaev, 1976).

Citing a document is an act of symbol usage. Cited documents symbolize ideas, methods or broader claims, to those who cite them, and over time, as citations accrue, cited documents may become "concept symbols". Developments towards "uniformity of usage" are obviously influenced by citers 
being "inspired" by what previous citers wrote. Eventually, a document may come to symbolize concepts, which its authors did not anticipate. It may be a method, a claim, or a general idea or topic. Small (1978) demonstrated, that citing authors tend to be both specific and highly uniform in the meanings they assign to cited documents, as revealed by the contexts of the references. However, as citation counts go up, many cited references tend to be used more uniformly and become 'concept symbols' to those who cite them. Such 'uniformity of usage' is usually beyond the control of the cited authors. For a typical work, Small (1978, p. p. 338) noted that "perhaps the most important result of the social selection of knowledge through citation is the narrowing of meaning which occurs". This narrowing has significant implications for knowledge dissemination, theory development and testing because it frequently eliminates important qualifications and nuances in the original work that may be essential. Cited references may very well become 'concept symbols' due to distorted citing practices, where citing authors, re-cite previous authors' citing context, perhaps without reading the original cited work.

Returning to the aforementioned paradox of citing; a work and its references can never, in the nature of things, reproduce or cite the full range of evidence they rely on (Grafton, 1997). A legitimate selection has to be made, something Merton also acknowledged (1979). Case and Higgins (2000, p. p. 635), in their study among communication researchers, claim that the most common reasons for citing were "that the work was novel, well-known, and a concept-marker"; that citing it might "promote the authority of one's own work"; and "that the work deserved criticism". Hence, motivations behind citing can seemingly be everything from relevance of the cited work in terms of topicality, novelty, usefulness, "intellectual debts" (positive as well as negative), to strategic and persuasive reasons which have little to do with "bestowing credit where credit is due" (Camacho-Miñano \& Núñez-Nickel, 2009; Cozzens, 1989; Liu, 1997; H. Small, 2004). Clearly, deviations from normative ideals may threaten the trust in citations as valid and reliable measures of recognition, but they may also harm the trust in a valid, reliable and effective system of scientific communication. 2.3 Biased citing and it consequences for the genealogy of the epistemic literature The practices leading to inadequate citation distributions or incorrect reference coverage not only have consequences for science's social institutions. They also impact directly on epistemic claims. Several scholars have shown, mostly through extended case studies, how problematic citing practices may lead to maintaining or instigating false claims. In a recent review, Leng and Leng (2020a) provide valuable insights into the important consequences of biased citing practices presenting a number of case studies. We will as a means of example briefly discuss two of these cases. In the first case, Greenberg (2009a) shows how a distorted citation distribution impacted the general understanding of how a particular protein, $\beta$-amyloid, impacted patients with a particular muscle-wasting disease, inclusion body myositis. With twelve empirical studies carried out, six claimed the protein to be abnormally present in patients with this disease, while the other six found no evidence for this claim. In addition, four of the supporting papers were from the same lab, with two based on the same dataset. All in all, evidence for the claim was weak. Nevertheless, the claim is often presented as a fact. Greenberg demonstrates how citation practices play a role in this. In his study he finds $94 \%$ of citations to primary studies were towards those supporting the claim, while only $6 \%$ cited one of the unsupportive studies. This renders a situation in which the literature shows an extreme bias towards accepting a, largely unproven, claim.

In another example, Trinquart, Johns, and Galea (2016) study the role of citation practices in the controversy around guidelines on the overconsumption of salt. While a large body of both supportive and unsupportive primary studies exists regarding the claim that overconsumption of salt is (generally) harmful to a certain class of patients, the citing literature contains very few traces of an ongoing controversy. In fact, Trinquart et al. note that: "The opposing camps disproportionately 
cited data that supported their positions; they used different data, from different types of studies. Even in systematic reviews, there was uncertainty over what should count as evidence. The salt controversy was comprised of two groups of scientists arguing past each other because they drew from different sources of evidence that led them to reach starkly different conclusions." (G. Leng \& Leng, 2020b, p. 170). This example hence shows that citations practices need not necessarily be distorted towards positive results. Rather, scientists may also just 'use' the literature that is most fitting to the narrative of their own manuscript.

Both cases exemplify how distorted citation distributions can have a lasting effect on the epistemic status of certain claims. These distorted distributions arise from citing practices that could be labelled questionable. The profound impact of these practices reflecting individual author's choices, demonstrates the responsibility that each author has in providing a critical and representative account of the academic literature. However, while understandable and legitimate the omission of some references may, step-by-step, lead the academic literature astray.

\section{Methods}

This article employs a case study approach to investigate problematic citing behaviour and its potential consequences. In particular, it focuses on one of the landmark papers in research on Questionable Research Practices published by John et al. (2012), hereafter called the John Study.

\subsection{The John Study}

In their study on Questionable Research Practices, John et al. (2012) conducted a survey among 2155 psychologists at major US universities. Participants anonymously responded to three different questions related to a set of nine selected QRPs and one on falsifying data. First, respondents indicated whether they had personally engaged in each of the selected QRPs, and if they had, whether they thought their actions had been defensible. Second, they estimated the percentage of other psychologists who had engaged in each behaviour, and third, they estimated the percentage of psychologists that would admit to having done so. Several incentives for truth-telling were used in order to maximize the likelihood of honest reporting. Combining the three different estimation methods, the study found that the percentage of respondents who engaged in questionable practices was "surprisingly high". This led them to the suggestion that "some questionable practices may constitute the prevailing research norm" (John et al., 2012)

The John Study has repeatedly been criticized (e.g. (Klaus Fiedler \& Norbert Schwarz, 2016; Pettigrew, 2018; Stroebe, 2016)), most notably in a study by K. Fiedler and N. Schwarz (2016). The main point of their criticism targets the methods used to estimate QRPs prevalence and essentially undermines the claim of widespread use of such practices. In particular, they argue that merely asking whether respondents have ever engaged in one of the listed QRPs gives little information about the QRPs prevalence, as long as no information on the share of articles affected by this behaviour is given. Including this aspect in a survey among German psychologists yielded prevalence estimates of orders of magnitude lower than the ones found in the John Study. Other critiques on the John Study target the purported effectiveness of the truth-telling incentives and the overgeneralisation of their claims.

The John Study is a highly cited paper in the fields of meta-research and research integrity, with 644 citations in Web of Sciemce at the moment of data sampling (November 2020). Therewith, it is part of the 'canon' of papers that are usually cited in relation to reproducibility concerns and QRPs. In 
combination with the flaws in its methodology that have been publicly pointed out (K. Fiedler \& N. Schwarz, 2016), this yields a particularly interesting case for an in-depth citation analysis. First, authors working in the field of research integrity might be expected to engage in proper citation behaviour as they should arguably be aware of the detrimental effects of problematic practices. The fact that the work's methodological shortcomings have been publicly pointed out should furthermore be expected to enhance additional caution in citing the John Study. Second, as this study's authors themselves work within this field, they have the relevant expertise to judge the accuracy and appropriateness of citations to the John Study. Third, the high number of citations obtained by the John Study allows for larger scale, quantitative analysis. Even though we acknowledge that using a case study approach has its inherent drawbacks, we believe that the current case is illustrative of a wider phenomenon of problematic citation practices, some of which have been highlighted previously (e.g. Greenberg, 2009b; G. Leng \& Leng, 2020b; R. I. Leng, 2018).

\subsection{Data sampling}

Articles citing the John Study were sampled through Web of Science on November 11 2020, yielding a set of 644 unique references. From the references, we selected a sample of 300 articles. Because of our interest in whether citing articles acknowledge the limitations of the John Study, we included all citing articles that also cite the study by K. Fiedler and N. Schwarz (2016). This comprised 51 articles. Because previous literature on citation analyses demonstrates that early references to a study decisively impact later citing behaviour, we also included all articles from the first two years after the appearance of the John Study. This comprised 42 articles. The other 207 articles constituting our analysis sample were randomly selected from the remaining overall reference set.

For the articles in the final sample, all citation contexts involving the John Study were extracted manually. This was first done for a pilot sample of 16 articles for which two of the authors independently coded the citation context, following a predetermined coding scheme. After this initial coding, all codings were compared, discrepancies were discussed in order to reach consensus on all, and the initial coding scheme was slightly adjusted to accommodate more accurate descriptions of the citation context. Subsequently the remaining 284 articles were coded independently by one of the authors ( 42 by JWS, 242 by SPJMH). In case of doubt, codings were discussed among the authors until consensus was reached.

Coding specifically focussed on how an article uses the John Study: perfunctorily (cases in which the citing article does not at all engage with the John Study and leaving out the reference would make no difference to the citing context), superficially (e.g. only mentioning the John Study as a way to introduce the general concept of QRPs or its prevalence in very general terms) or substantively (explicitly engaging with the content of the John Study).

In case of a superficial reference, we checked whether:

- More appropriate references are also given, e.g. references to earlier papers introducing the concept of QRPs.

- Whether the article refers only to the concept of QRPs or also to its prevalence (in very general terms) and/or the methods used in the John Study.

In the case of a substantive reference, we checked whether the citation:

- Reproduces John et al.'s main claim that QRPs are widespread in psychology and/or whether it generalizes this to other fields or science as a whole. 
- Reproduces sub claims made in the John et al. paper, for instance regarding individual QRPs or researchers' perceptions of QRPs' defensibility. Again we checked for the validity and accuracy of the reproduction of the claims.

- Makes any claims that are not made in the John Study.

- Engages in a critical way with either the prevalence claims or the employed methodology of the John Study.

For both superficial and substantive references, we additionally coded whether the citing paper:

- Cites the paper by K. Fiedler and N. Schwarz (2016), and if so, whether it makes reference to the (methodological) issues in the John paper raised by Fiedler et al. (only relevant if the article was published after 2016)

- Draws attention to any other methodological critiques on the John Study.

- Uses reserved or passive language to describe the results in the John Study (i.e. reports the findings without necessarily expressing support for them).

All these aspects were coded on a binary yes/no-basis.

Supplementary material A contains an overview of some illustrative citation contexts for the different parts of the coding scheme.

\subsection{Data analyses}

Following the above coding scheme, the empirical analyses ask the following questions:

- How often is the John Study cited - including distribution of citing papers over publication years, scientific disciplines and article sections?

- How does this distribution over disciplines correlate with the severity in which the disciplines are thought to be affected by the 'replication/credibility crisis'?

- What percentage of these citations is perfunctory or superficial (e.g. only mentioning the reference as a way to introduce the general concept of QRPs) and how many of the articles using this kind of reference also cite more appropriate references?

- What percentage of the references is substantive?

- How many of those accurately represent the claims in the John Study?

- How many of those acknowledge the issues raised by Fiedler \& Schwarz? (i.e. how many cite Fiedler (2016) and reproduce their criticism?)

- In what part(s) of the citing articles is/are reference(s) to the John Study made?

- How are perfunctory, superficial and substantive references distributed over publication years, disciplines and article sections?

- To what extent do superficial and substantive references critically engage with the John Study?

- Do they directly engage/use their own arguments, do they cite Fiedler (and use it critically), or do they use other references?

\subsection{The genealogy of citations - tracing concept symbols}

The John study is highly cited. It attained that status rather quickly and is therefore likely to have become a concept symbol to many of its citers. Becoming a concept symbol takes time. Initial citing will be more diverse and evidently be based on abstract or full text reading of the cited document. As citing documents are published and citing contexts become visible to future citers, the process of 
"uniformity of usage" may evolve. It is therefore relevant to examine early citing contexts in order to understand the symbol usage here, and then compare it to the latest citing contexts in order to examine the extent to which the cited document can be seen as a concept symbol.

We analyzed the citing contexts using a simple categorization scheme. The categorization process has been bottom-up, so that categories have been established and adjusted along the way. We used eight categories, distributed over three levels. Level 1 is the most specific, where the citing context engages directly with the John survey, or an individual practice, or some other specific feature of the paper not related to the prevalence findings. Level 2 is for "broader claims". Level 3 contains "general claims", or what may be considered over time to be "concept symbols". Finally, two other categories are not assigned to a level: one that contains citing contexts that seem to be some cognitive distance away from the John study (or simply perfunctory); and a category which accounts for the co-citing of the John and Fiedler studies.

We examine the distribution of codes across citing contexts between two time frames, 2012-13 and 2020. We include all citing documents form 2012-13 (40,67 contexts) and a random sample from 2020 ( 21 out of 87,30 contexts). We are interested in examining potential shifts among the category levels, where we would expect citing contexts to become more general over time if the John study is becoming a concept symbol to many of those who cite it. For more information on the methodological approach for this analysis, we refer to the supplementary materials.

\section{Results}

\subsection{General description}

Figure 1 presents a general overview of the full set of 644 articles citing the John Study, indicating the publication years and the WoS category (of the journal) in which the article is classified. The figure shows a fairly generic distribution of citations to the John Study since its appearance in 2012 with a steady grow in citations every year. It also indicates co-citations to the study by K. Fiedler and N. Schwarz (2016) and Steneck (2006), where the latter is generally accepted to be the first study properly introducing the concept of QRPs in the broader scientific literature. Interestingly, while the Fiedler Study attracts a small number of co-citations with the John Study after its appearance in 2016 hardly any co-citations occur to the Steneck Study, in particular not in the early studies citing the John Study.

The distribution over research fields, presented in Figure $1 b$, demonstrates that the John Study is mainly cited from the field of Psychology. This is not surprising as the John Study itself is published in a Psychology journal, uses psychologists as its study population, and since the debate about research integrity and QRPs generally has been prominent in this field of research. Nevertheless, the John Study also obtained citations from studies from a broader array of disciplines, including social science disciplines (Management, Business, Economics) and biomedical disciplines (Neuroscience, Biology). 


\section{Citation Count}

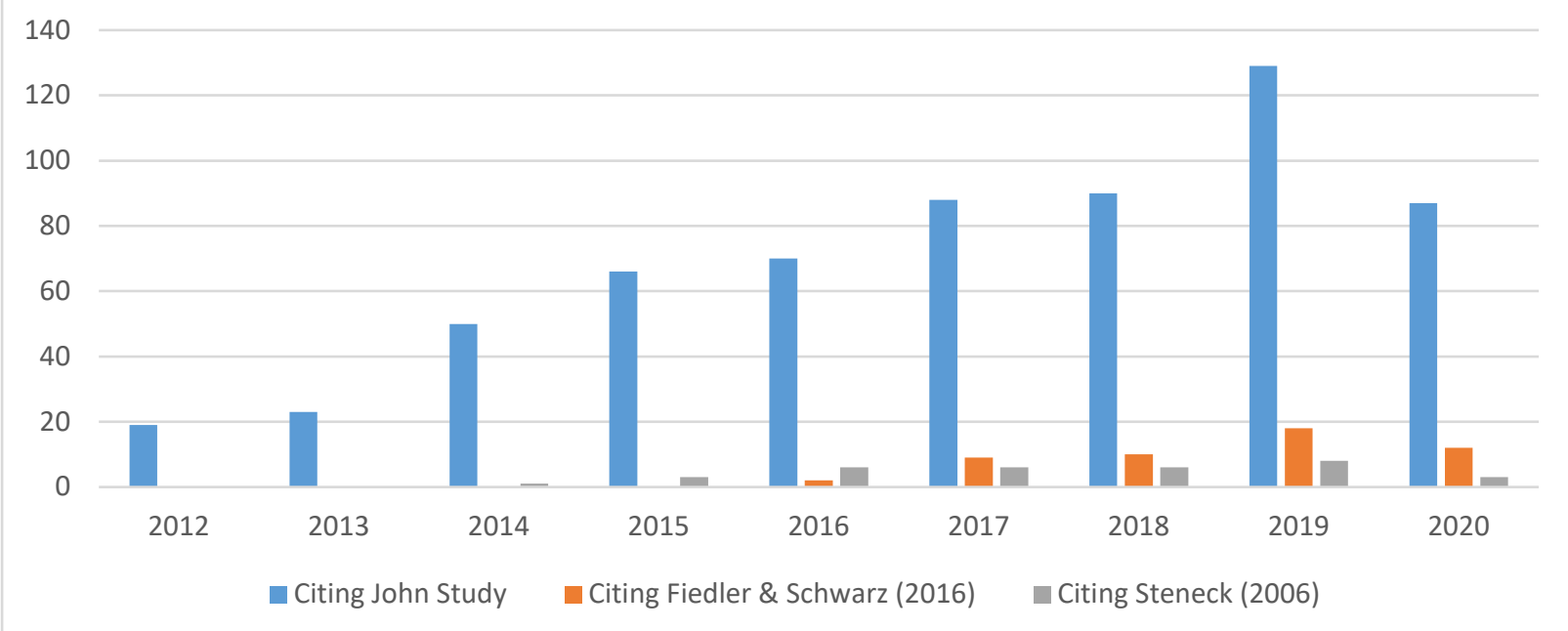

Figure 1a - The number of citations per year to the John Study, as well as the number of co-citations to the studies by Fiedler and Schwarz (2016) and Steneck (2006)

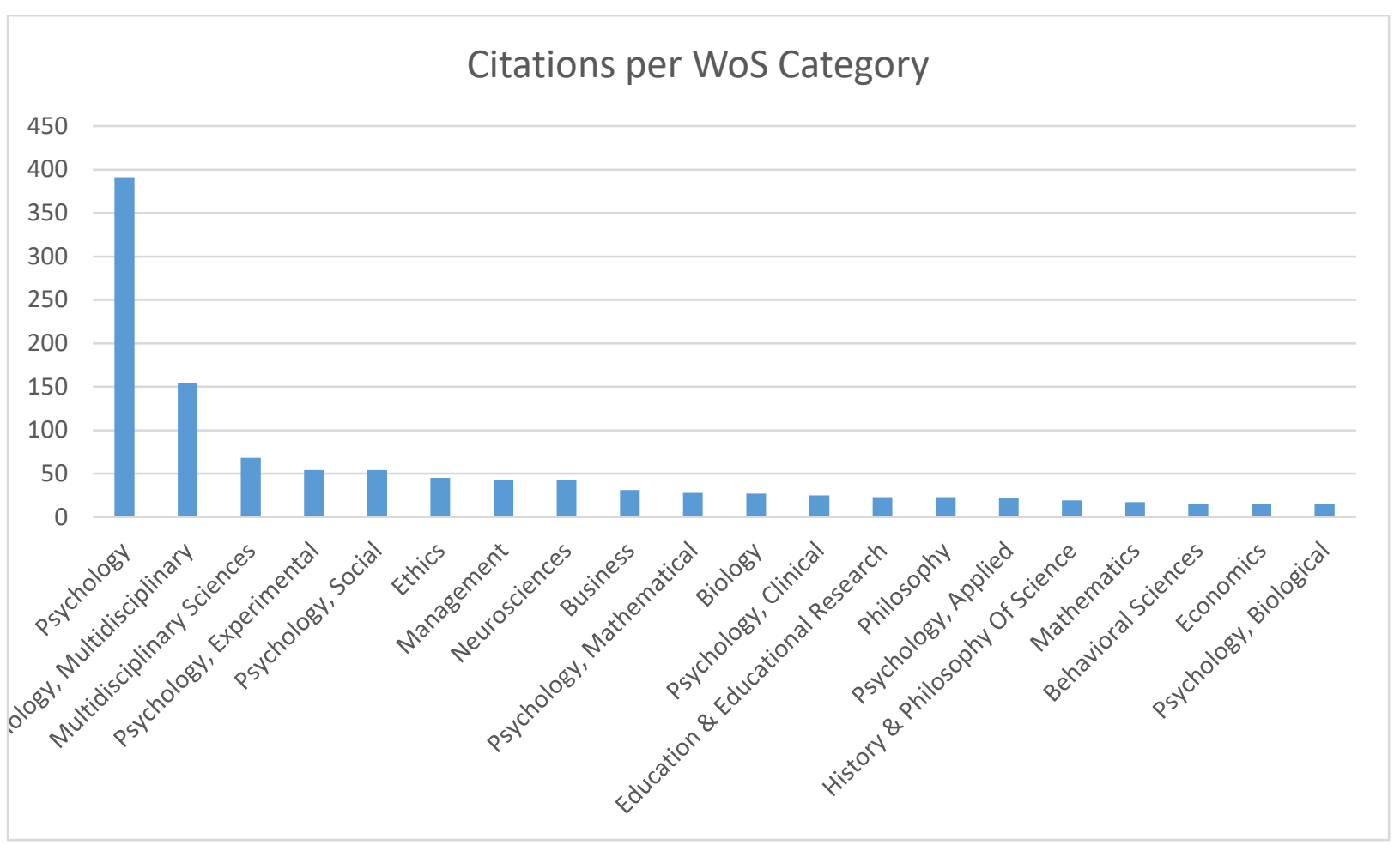

Figure 1b - The distribution of citations to the John Study over the twenty most prevalently occurring research disciplines in the citing literature. Research disciplines are assigned according to Web of Science categories.

Subsequently, we zoom in on the set of 300 articles for which the coding analyses was performed. Out of this set, nineteen articles could not be coded because the authors either had no access to the article's full text (sixteen articles), because of unresponsive webpages (two articles) or because the John Study was only mentioned in the reference list, but was not actually cited in the article's main text (one article). The remaining 281 articles contained 450 citation contexts in which a reference to the John Study was made, i.e. citing the John study on average 1,6 times each (range $1-11$ ). Tables 
1 and 2 provide a general overview of the main coding elements assessed in our analyses. In particular, they present the distribution of citation contexts over the main categories (substantive, superficial, perfunctory), distinguishing between superficial references making general remarks about the prevalence of QRPs and those merely referring to the concept of (specific) QRPs.

\begin{tabular}{|c|c|c|c|c|c|}
\hline Citation context category & Total & Substantive & Superficial & $\begin{array}{l}\text { Superficial } \\
\text { referring to } \\
\text { prevalence }\end{array}$ & Perfunctory \\
\hline Total & 450 & $123(27 \%)$ & 257 (57\%) & $103(23 \%)$ & 70 (16\%) \\
\hline $\begin{array}{l}\text { Reproduces John Study's main } \\
\text { claims - Doing so correctly }\end{array}$ & $\begin{array}{l}42-28 \\
(67 \%)\end{array}$ & $\begin{array}{l}42-28 \\
(67 \%)\end{array}$ & & & \\
\hline $\begin{array}{l}\text { Reproduces John Study's sub } \\
\text { claims - Doing so correctly }\end{array}$ & $\begin{array}{l}93-74 \\
(80 \%)\end{array}$ & $\begin{array}{l}93-74 \\
(80 \%)\end{array}$ & & & \\
\hline $\begin{array}{l}\text { Referring to broad prevalence } \\
\text { claims - Doing so correctly }\end{array}$ & $\begin{array}{l}103-50 \\
(49 \%)\end{array}$ & & $\begin{array}{l}103-50 \\
(49 \%)\end{array}$ & $\begin{array}{l}103-50 \\
(49 \%)\end{array}$ & \\
\hline
\end{tabular}

Table 1 provides information on the general distribution of citation contexts over the main categories as well as information on the correctness of claims reproduced from the John Study. From the data presented in this table, we can discern at least two interesting observations:

i. Only about one quarter (123/450) of all citation contexts contain a substantive reference to the John Study. An additional nearly quarter of the sample (103/450) only superficially references the John Study, but does refer to the prevalence of QRPs in very broad terms.

ii. A substantial number of citation contexts incorrectly reproduce claims from the John Study. This number ranges from over 50\% (53/103) for the superficial references reproducing prevalence claims, to $33 \%(14 / 42)$ for substantive references reproducing the John Study's main claims, to about 25\% (19/93) for substantive references reproducing sub claims from the John Study.

\begin{tabular}{|c|c|c|c|c|c|}
\hline Citation context category & Total & Substantive & Superficial & $\begin{array}{l}\text { Superficial } \\
\text { referring to } \\
\text { prevalence }\end{array}$ & Perfunctory \\
\hline Total & 450 & $123(27 \%)$ & $257(57 \%)$ & $103(23 \%)$ & $70(16 \%)$ \\
\hline Citing Fiedler & 75 (17\%) & $32(26 \%)$ & 43 (17\%) & & \\
\hline $\begin{array}{l}\text { Citing Fiedler in this citation } \\
\text { context }\end{array}$ & $33(7 \%)$ & $19(15 \%)$ & $14(5 \%)$ & & \\
\hline $\begin{array}{l}\text { Critically citing Fiedler in this } \\
\text { citation context }\end{array}$ & $18(4 \%)$ & $15(12 \%)$ & $3(1 \%)$ & & \\
\hline Mentioning other critiques & $5(1 \%)$ & $5(4 \%)$ & $0(0 \%)$ & & \\
\hline $\begin{array}{l}\text { Critically engages with the John } \\
\text { Study }\end{array}$ & $29(6 \%)$ & $26(21 \%)$ & $3(1 \%)$ & & \\
\hline $\begin{array}{l}\text { Critically engages with } \\
\text { prevalence claims }\end{array}$ & $21(5 \%)$ & $18(15 \%)$ & $3(1 \%)$ & & \\
\hline
\end{tabular}


Critically engages with methods $18(4 \%) \quad 18(15 \%) \quad 0(0 \%)$

employed in the John Study

Table 2 - Distribution of citation contexts over the main coding categories as well as information on whether and how

the citation contexts critically engage with the cited literature and whether any awareness of critiques on the John Study

is shown.

Table 2 presents information on the level of critical engagement with the John Study. It documents how many of the citation contexts refer to the Fiedler Study or other critiques of the John Study, and how many citation contexts critically engage with the John Study to start with. This leads us to another two observations:

iii. From the small set of citation context appearing in papers also citing the Fiedler Study (75), only a minority contains a co-citation in the same citation context as where the reference to the John Study is made (33/75), and from those only just over half actually refers to the critiques or concerns expressed in the Fiedler paper (18/33). In total, this means that in all cases that authors show awareness of the Fiedler Study by citing it, and hence should be expected to have read it and be aware of its critical content towards the John Study, only about $25 \%$ expresses this when citing the John Study. Generally, the total number of citation contexts showing awareness of Fiedler and Schwarz' criticisms $(18 / 450)$, is extremely low. This has clear implications for the epistemic genealogy of the claims made by the John Study. Note here that, owing to our specific interest in critical engagement, we included all articles citing the Fiedler study when we composed our sample of citation contexts to be coded, out of the total set of articles citing the John Study (see section 3.2 for details). Hence, the share of articles citing the John Study without showing awareness of its flaws, should be expected to be even smaller in the total set.

iv. Similarly, the number of citation contexts mentioning other critiques (5/450) or in any way critically engaging with the content of the John Study (29/450) is remarkably low.

\subsection{Where things go wrong: qualitative analysis}

The results of our qualitative context analysis also suggest that over time the John study is becoming a concept symbol. Here - as described in Section 3 - we carry out a more detailed comparison of citation contexts in two different periods: 2012-2013 and 2020. Each citation context is here assigned to one of three levels based on how specific or general the claim is stated. Focussing specifically and more in-depth into the earliest and most recent citations, allows us to trace the genealogy of citations to the John Study. One third of the citing contexts in 2020 refer to the "widespread use of questionable research practices", and slightly more than one in ten refer simply to "questionable research practices". Many contexts do not specifically refer to Psychology, but most citing documents are published in psychological journals so this restriction may be implicit. Combined, Level 3, comprising the general claims, constitutes almost half of all citing contexts in 2020. In the 2012-2013 sample, that fraction was one in five. The shift demonstrates that early on, citing contexts are more diverse and spread out between the three levels. What seems to have happened is that Level 2, consisting of broad claims, has shrunk to almost nothing, presumably, because this "broader context" has seen a gradual "uniformity of usage" moving towards an even more general symbolic use of the John study, Another interesting pattern is that the frequency of Level 1 citing contexts seems to be rather consistent over time. This means that while cited 
documents may become concept symbols, and as such are typically cited in the introduction or review sections of a paper, they are also still cited for specific reasons, which indicate a direct involvement with parts of the study.

\subsection{Patterns in citing behaviour and contexts: quantitative analysis}

Diving a bit deeper into the quantitative analyses several additional patterns can be distilled. We present them in this sub section. The patterns concern the distribution of citation context categories over publication years and research disciplines. We also examined the distribution of references to the John Study over article sections but no clear patterns were found.

Figure 2a shows the distribution of citation contexts' categories over publication years, since the appearance of the John Study in 2012. Interestingly, while a large majority of citations in 2012 were superficial, the shares of substantive and superficial references were nearly equal for several of the subsequent years. From 2017 onwards, the share of substantive references drops and superficial references again make up the vast majority of citations to the John Study. Figure $2 b$ moreover presents the share of references that correctly reproduce the claims in the John Study. Also here, we see a substantial drop for citations in the substantive category for the latest years. Combined, this means that the most recent references to the John Study, i.e. those in 2019 and 2020, only contain between ten and twenty per cent of presumably correct substantive citations. Notice however, that 'correct' here not necessarily implies also mentioning the critique of the study. Hence, the number of citations that are both substantively correct and presented along an acknowledgement of the flaws of the study is likely to be even lower.

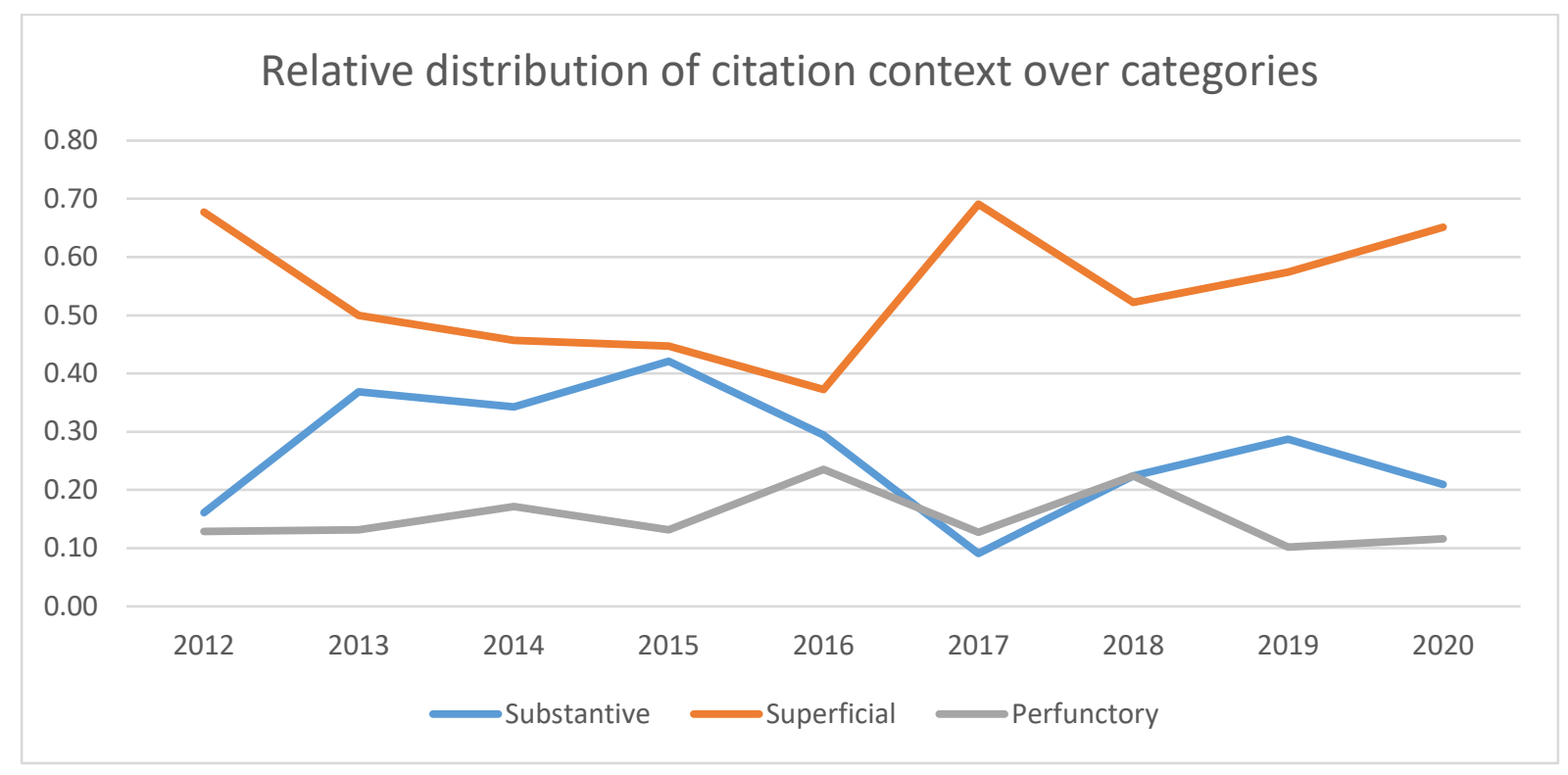

Figure $2 \mathrm{a}$ - The relative distribution of the citation contexts over the three main coding categories per year. 


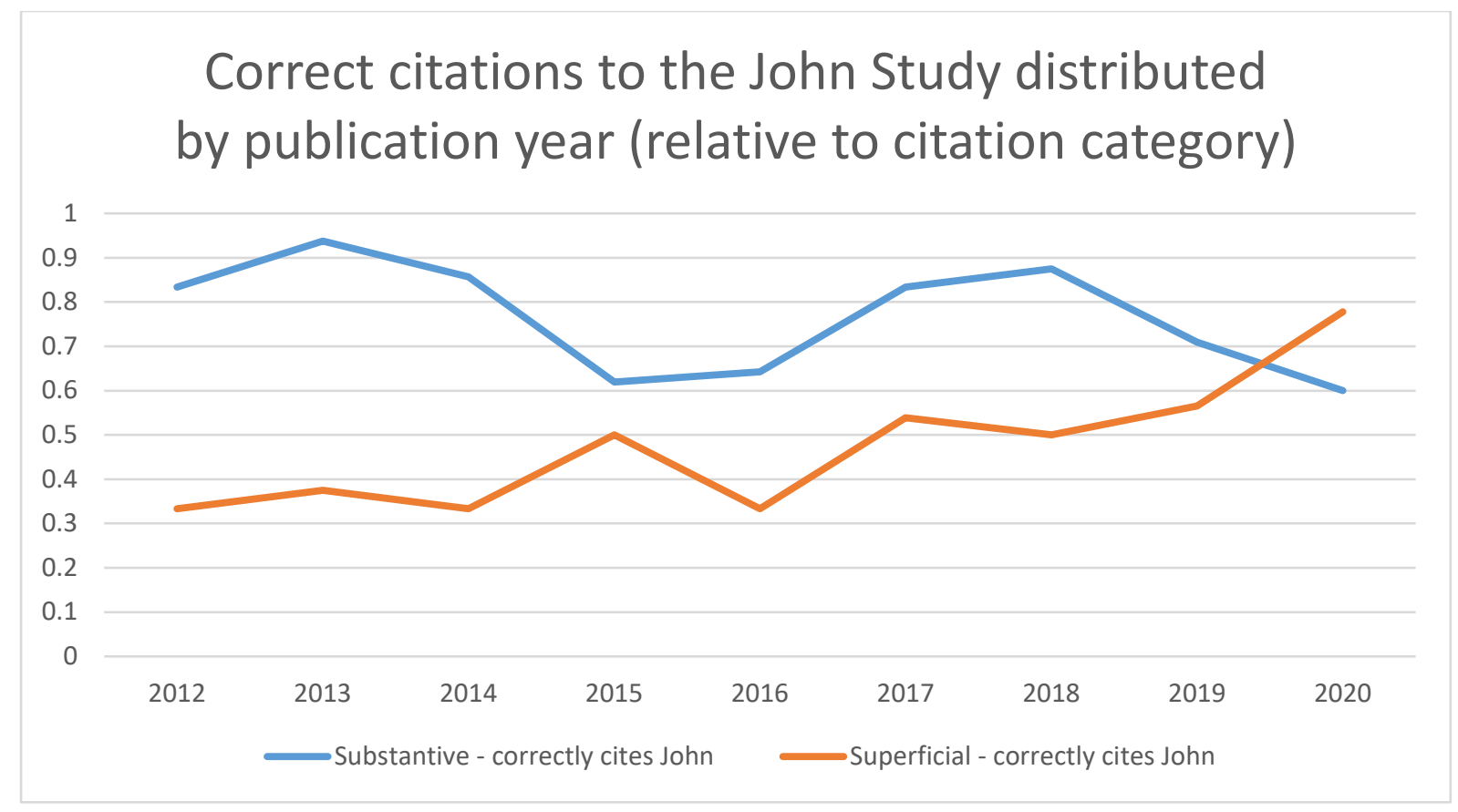

Figure $\mathbf{2 b}$ - The share of citation contexts correctly reproducing claims from the John Study per year for the coding categories 'substantive' and 'superficial'.

Besides these developments in citation contexts over the years, a noticeable pattern is discernible when considering the disciplinary background of papers citing the John Study. Figure 3a presents the distribution of citation contexts over WoS categories, showing the ten most frequently occurring categories. As we saw earlier, Psychology accounts for the majority of references, followed by the multidisciplinary sciences, Ethics, and Management sciences. Figure 3b presents the way in which these citation contexts engage with the criticisms on the John Study raised in the Fiedler Study. It demonstrates how many of the citation contexts come from articles also citing the Fiedler Study, how many of those do so in the same citation contexts as where they cite the John Study, and how many of those actually mention the critiques raised by Fiedler \& Schwarz. Here we see several substantial differences in citing behaviour between the various disciplines, with some not engaging (critically) at all with Fiedler (Mathematics, Management, Neuroscience and Behavioral Sciences) while others critically engage with Fiedler in all instances that the study was cited in the first place (Philosophy and Engineering). It is noteworthy that citations from studies being epistemically distant to the John Study (e.g. Philosophy, Engineering, Ethics) are more likely to critically engage with the critiques from Fiedler's study than citations from more closely related disciplines (Psychology, Business, Management, Behavioural Sciences), in case the authors show awareness of the Fiedler Study. Notice however, that the total number of citations given to the study in non-Psychology disciplines is low. The observed patterns should therefore be interpreted with caution. 


\section{Distribution over WoS Categories (absolute numbers)}

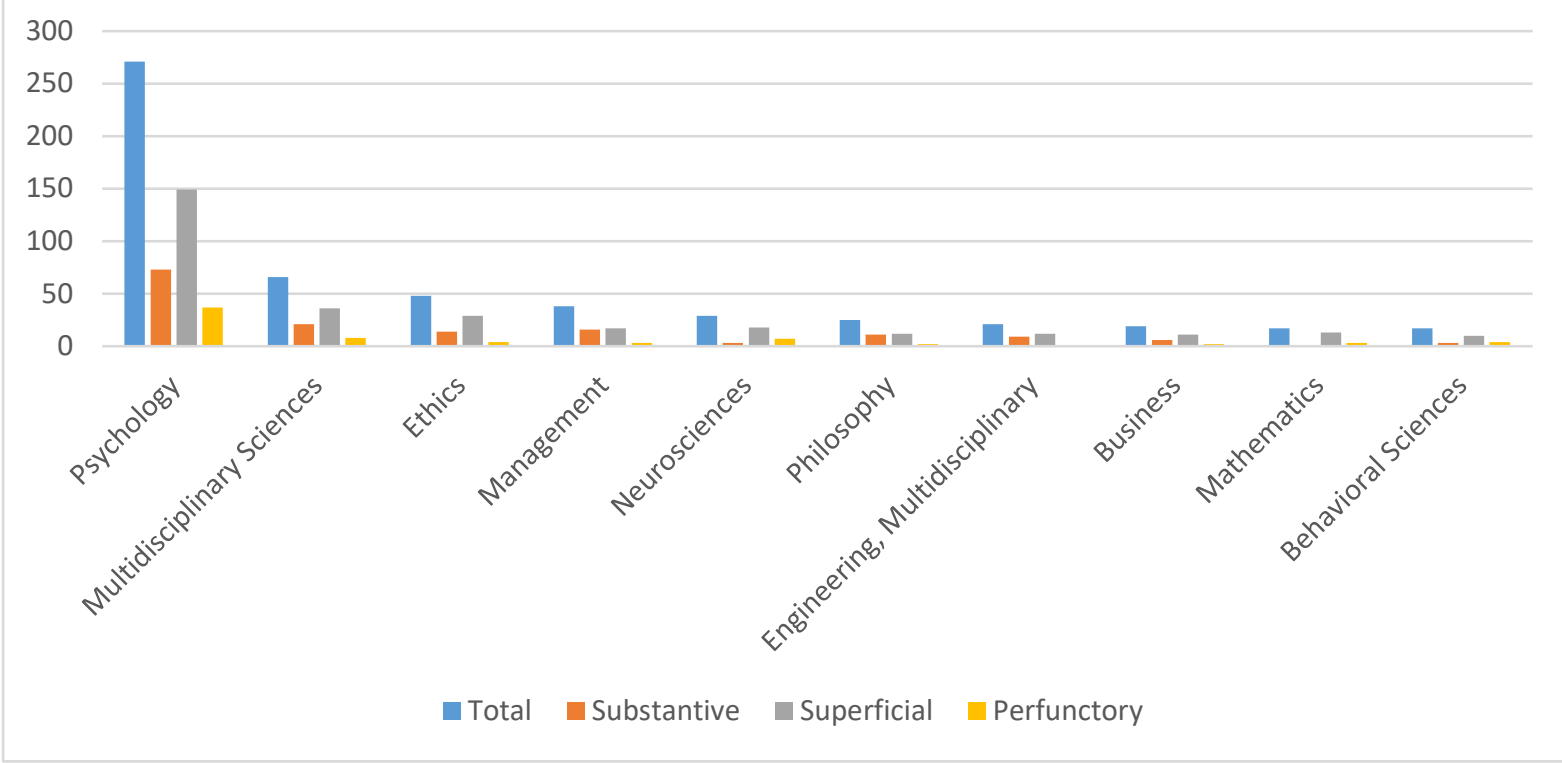

Figure $3 a$ - Distribution of the citation contexts and their main coding categories over the ten most commonly occurring research disciplines. Research disciplines are assigned according to Web of Science categories.

\section{Citing behaviour to Fiedler, distributed over WoS \\ Categories \\ (relative numbers)}

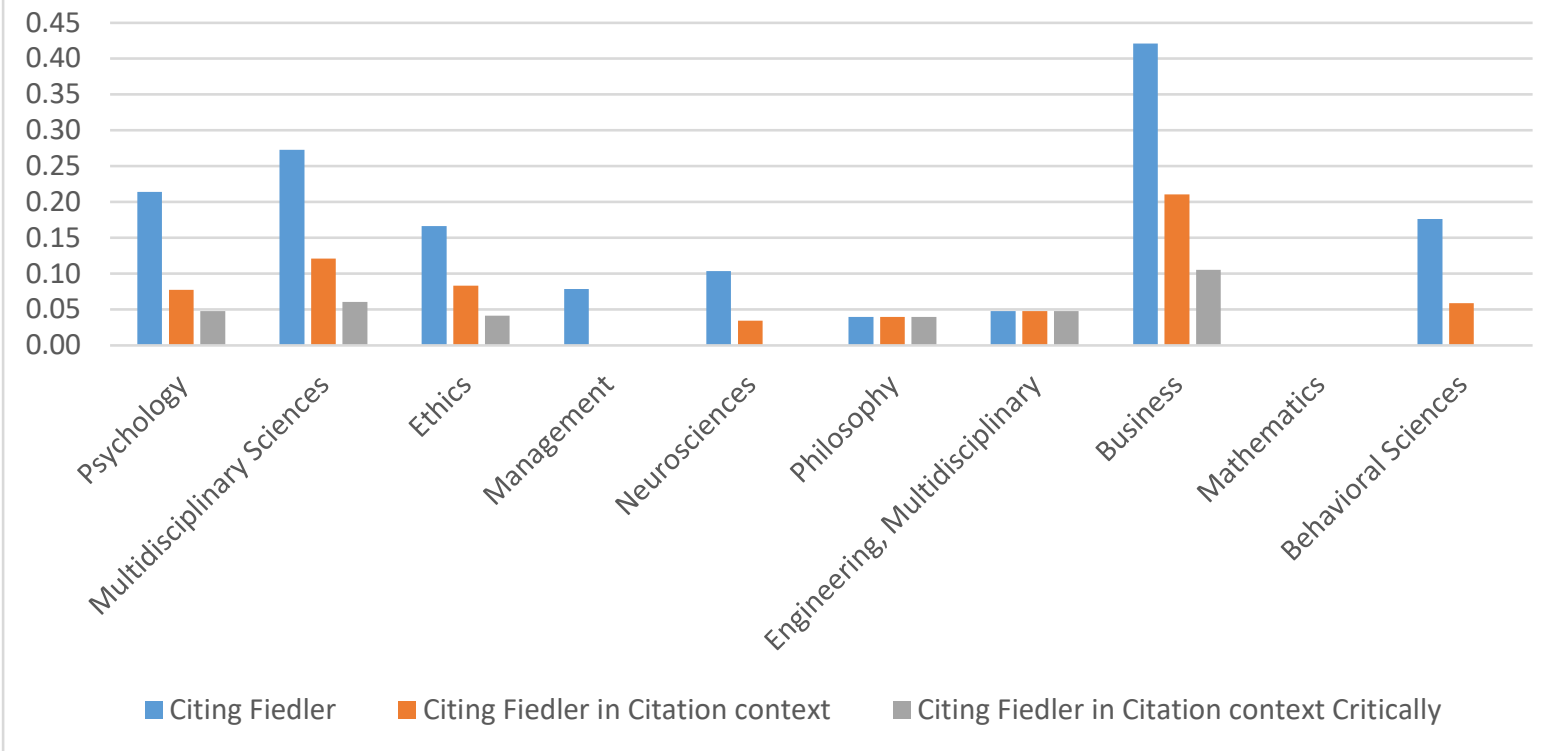

Figure $3 \mathrm{~b}$ - The share of citation contexts co-citing the Fiedler Study in the same article, the same citation context, and within the same citation contexts while showing awareness of Fiedler \& Schwarz critique on the John Study. Distribution of citation contexts over the ten most commonly occurring research disciplines. Research disciplines are assigned according to Web of Science categories. 


\section{Discussion: How exemplary is this study for questionable citing practices}

In this section we will reflect on the findings presented in the previous section, discuss credible interpretations of the patterns found, and relate them to previous findings reported in the research literature.

\subsection{Genealogy of citations - from substantive to concept symbol}

Besides playing a role in documenting the genealogy of epistemic claims, citations also have a genealogy of their own. As our results indicate, the references to the John Study tend to decreasingly engage with the original study as time passes by. Whereas references in the first years after publication of the John Study tend to be substantial in nature, they are mainly superficial in recent years. In addition, the number of references correctly reproducing the claims from the John Study is dropping over time. This phenomenon has been identified before (Schneider, 2006; H. G. Small, 1978). As we show in the qualitative context analysis, the process can be meaningfully described as the 'tokenisation' of references: as time passes by, highly cited papers tend to become a concept symbol of a particular concept. Citations to the study no longer engage with its actual content, but merely refer to the object of study, in this case 'Questionable Research Practices', or a particular method or very general claim. As the context analysis indicates, the main claim of the John Study seems to have become a meme that "lives a life of its own" due to biased citing practices. Given the criticism of, among others, the Fiedler Study, it seems evident that the main claim of "widespread use of QRPs" cannot stand alone. If it does, the claim is flawed and the citing practice is distorted. It is also interesting that the "general claims" we find in the citing contexts, either just the existence of QRPs or their high prevalence, both appear in the abstract of the John paper, which might have intensified the process of becoming a concept symbol. .

\subsection{Lack of critical engagement}

The finding that only a remarkably small share of papers citing the John Study critically engages with its claims or methods, also raises a host of questions. This citing behaviour indicates a rhetorical or persuasive use of citations rather than a substantive one. As others have noted (e.g. J. P. Ioannidis, 2018), highly cited papers tend to benefit from a citation-Mathew effect, that leads certain studies to be cited far more often than their academic contribution warrants. This is not only detrimental for science's internal reward system, it also leads to a reduction of epistemic diversity. In cases such as ours, where the findings of a study have met severe criticism, this lack of critical engagement with the cited study also has clear epistemic consequences.

As discussed in the previous subsection, critical engagement with a study tends to drop even further as time passes by. This in turn makes the citations susceptible to reproduction of incorrect citations, resulting in citation strings that increasingly diverge from the original study's findings. We all know how a typical game of Chinese whispers ends.

Even though this should ideally not happen in science, where we should expect authors to read their original sources rather than copy references from other papers they read, multiple studies have indicated this practice to be prevalent (Jergas \& Baethge, 2015; G. Leng \& Leng, 2020b; Stang, Jonas, \& Poole, 2018). In fact, most researchers seem to read only a small proportion of the studies they cite. The findings in this analysis give further reason to doubt the connection between researchers' reading and citing practices. As discussed in section two of this article, this can have considerable 
consequences for both the epistemic validity of scientific claims and for the social arrangements and recognition structures in science.

\subsection{Disciplinary variation}

Another remarkable pattern among our findings constitutes the differences between citing behaviour between diverse scientific disciplines. In particular, authors showing awareness of the Fiedler Study were more likely to critically engage with the study's critiques on the John Study when such authors came from epistemically distant disciplines (e.g. Philosophy, Engineering, Ethics) rather than coming from more closely related disciplines (e.g. Psychology, Business, Management, Behavioural Sciences). Again, it should however be noticed that this observation rests on a relatively low number of absolute cases and hence that the finding should be treated with more caution than the rest of the results.

The fact that citation practices differ between disciplines should however not come as a surprise as it has been widely documented before (e.g. Hargens, 2000). Here, our findings additionally give rise to the observation that authors from diverse fields appear to differ in their level of critical engagement with the studies they cite. Future studies could assess whether the difference in critical engagement is inherent to the disciplines we study, or whether it is attributable to the epistemic distance between the citing and cited study. In case of the latter, this would in fact be an encouraging finding, suggesting that researchers tend to put more effort in reading articles that are out of their familiar knowledge base and are hence potentially more difficult for them to understand. In case the former explanation is found to be more plausible, it raises further questions about the reasons and dynamics behind this finding, including questions about differences in publication pressure between different research fields, or differences in academic norms and standards.

\subsection{Limitations}

Several factors may limit the accuracy or generalizability of our findings. This includes first and foremost the fact that our findings are based on a single case study. Nevertheless, we argue that this case is well-suited for our purpose and illustrative of a more general set of practices. In the next section we provide detailed arguments for this claim. In addition, our findings align well with previous studies on citation behaviour and their potential distorting effect on the scientific literature.

Second, the generally known diversity in disciplinary citing behaviour may limit the generalizability of our findings. Indeed, both the number, style and status of citations in a physics paper will differ from those in an article on medieval English literature, or a medical case report. Particularly, the decision on what to cite might be less complex in research fields that have achieved more theoretical closure. In contrast, researchers in fields characterised by more epistemic diversity might have a more difficult task in selecting and coherently presenting their references. While our case concerns a field that is arguably within this latter category, we still argue that the problematic aspects of citing behaviour identified in our study are indicative of a widespread set of behaviours. This argument is backed-up by similar findings in other fields, including Neuroscience (G. Leng \& Leng, 2020b), Medicine (Jergas \& Baethge, 2015) and Molecular Biology (Greenberg, 2009b). 
Third, our study may have been affected by coders' interpretation of citation context. Both coders are, however, well-versed in the field of research integrity and multiple efforts were undertaken to ensure inter-coder agreement (see methods section). Some level of (inter)subjectivity in classifying the citations can nonetheless not be prevented.

Fourth, we only had access to the written records including the citations and hence cannot rely on authors' motivations about why they did, or did not cite any particular study. Claims about authors' motivations, citing mechanisms, or level of actual engagement with the cited literature can hence not be inferred from our data.

\section{Conclusions}

Based on a case study of a highly cited paper in the field of research integrity, this article has highlighted a host of problematic or undesirable citation practices. Specifically, it has demonstrated that few citing articles critically engage with the cited study, leading citations to develop into concept symbols and incorrect representations of the cited study. These are in turn reproduced and spread. In our case, with the existence of an article strongly and validly criticising the highly cited paper, few of the other citing papers take note of these criticisms. In fact, only a very small proportion co-cites the critical study and of those, only a small minority reproduces the criticisms. This interferes with both main functions of citations: the social reward function (giving insufficient credit to the critical study and arguably disproportionally much credit to the highly cited John Study), and the epistemic genealogy function (upholding and spreading the claims from the highly cited John Study, even though their correctness and interpretation remain questionable).

Even though our findings are based on a single case study, we argue that the citation practices identified in our sample are likely to be illustrative for the wider scientific literature. Indeed, several other studies have highlighted the existence of sloppy, selective or otherwise problematic citation behaviour and many of these practices have been confirmed in our study. In our case this is particularly striking since our study deals with a highly cited study in the field of research integrity and questionable research practices. If any, one would expect authors in this area of research to be particularly aware of the potential detrimental consequences of problematic citing behaviour. The fact that such behaviour is as prevalent in our sample as it was reported in other areas of research, is both confirming earlier claims and deeply alarming.

Another argument supporting the claim that the tendency found in our study is more widespread, relates to the fact that the John Study makes particularly strong claims, through a clear and coherent narrative. In their citing behaviour researchers often use and reward strong claims because they (appear to) have more weight when one wants to prove a point or support an argument. Thereby, citations play an important role in the balancing act for researchers to make claims that are both justifiable with respect to the existing literature and new data, as well as novel or interesting, in order to warrant publication (Myers, 1985). More humble and less clear-cut results are less likely to be used because they often challenge clean narratives - even though their results are likely to be more "correct" or robust. This tendency biases the whole literature in a direction of overclaiming, overgeneralisation and exaggeration.

\subsection{Some attenuating circumstances?}


As highlighted in Section 2, we cannot cite everything that influences our research. There are restrictions due to formats or guidelines. Some references will be seen as necessary, others only as optional although such distinctions often are clearly debatable. Furthermore, while selection of what to cite has a normative aspect, the way we present the cited work may also be biased or distorted. This may be done by intention or unintentionally without engaging with the actual reference. Likewise, the motivation behind citing and the decision to cite a particular reference may be informed and rational, where the relevance of the cited reference is both evident and justified. But the process can also be much more complex. It may not be well-informed, it may be based on heuristics, bounded rationality or even sloppy procedures. Authors may not invest sufficient effort in reviewing the potentially relevant literature eligible for citing. They are thus likely to end up citing what is familiar to them, i.e. what they have cited before or the work of authors they know. Authors may also cite what others cite in somewhat similar contexts, perhaps even without reading it. Easy access to online citation indices is likely to have contributed to such more "sloppy" citing practices. Hence, researchers may often practice the "principle of least effort" (Zipf, 1949), not investing the necessary efforts to be able to select the most pertinent references and cite them in a correct and trustworthy way.

In addition, citing is also influenced by well-known cognitive constraints such as confirmation bias (Bishop, 2019). However, while this certainly produces bias, it may still to some extent result in the citing of relevant references. But while relevant, these may not be the most relevant. Others should perhaps have been co-cited, or alternatives could have been chosen. Obviously, motivations behind decisions to cite can also be of a more strategic, intentional nature, where selection and citing aim at persuading or promoting one's own work. This may happen by deliberately omitting references to relevant works or by misrepresenting the ones cited. In such cases, the citing practice not only becomes biased, it becomes questionable and distorted. Such selective citing may shape the scientific literature in damaging ways. In order for references to maintain their primary functions, as most would agree is necessary, some minimal standards for citing practices need to be upheld. This includes avoiding erroneous citing, not propagating claims which cannot be ascribed to the reference, avoiding re-citing without reading, and so forth.

\subsection{Consequences}

More generally, the distorted citation practices identified in this and other studies have major implications for the well-functioning of science. As mentioned in section 2, citation practices form the backbone of quality assurance mechanisms in science. In order to adequately fulfil this role, every time a citation is given, researchers ought to conduct an assessment of the cited reference. Hence, some kind of evaluation of the validity of the cited claims needs to take place every time a study is engaged with. This is not something that is handled once and for all at the formal stage of editorial peer review. As has been known for long, but is currently highlighted by the replicability crisis, one cannot take studies at face value when citing them. Instead, one should critically engage with the cited content prior to building new work upon it. This also highlights the individual responsibility of each and every researcher to uphold high integrity standards in all aspects of their work. Quality assurance and quality control is not something that is outsourced to journals or peer reviewers. Rather it is integral to all our daily routines where the engagement with other studies very often plays a crucial role. If we care about validity, trust in scientific findings and about the fairness of our evaluation systems, our own citing practices are the right place to start.

Some might argue that such citing expectations are unfeasible or puts an unrealistic burden on researchers, especially in a time when they are already pressed by an abundance of responsibilities and other expectations. However, if this duty of critical engagement cannot be met, this has drastic 
implications for the status of citations in academic research. It would, among others, require us to fully reconsider the role they can play in research evaluation and scholarly communication. 


\section{References}

Aksnes, D. W., Langfeldt, L., \& Wouters, P. (2019). Citations, Citation Indicators, and Research Quality: An Overview of Basic Concepts and Theories. SAGE Open, 9(1), 2158244019829575. doi:10.1177/2158244019829575

Anderson, M. S. (2000). Normative orientations of university faculty and doctoral students. Science and Engineering Ethics, 6(4), 443-461. doi:10.1007/s11948-000-0002-6

Anderson, M. S., Ronning, E. A., De Vries, R., \& Martinson, B. C. (2010). Extending the Mertonian Norms: Scientists' Subscription to Norms of Research. The Journal of Higher Education, 81(3), 366-393.

Baldi, S. (1998). Normative versus Social Constructivist Processes in the Allocation of Citations: A Network-Analytic Model. American Sociological Review, 63(6), 829-846.

Banks, G. C., Ernest H. O'Boyle, J., Pollack, J. M., White, C. D., Batchelor, J. H., Whelpley, C. E., . . Adkins, C. L. (2016). Questions About Questionable Research Practices in the Field of Management. Journal of Management, 42(1), 5-20. doi:doi:10.1177/0149206315619011

Bird, A. (2018). Understanding the Replication Crisis as a Base Rate Fallacy. The British Journal for the Philosophy of Science. doi:10.1093/bjps/axy051

Bishop, D. V. M. (2019). The psychology of experimental psychologists: Overcoming cognitive constraints to improve research: The 47th Sir Frederic Bartlett Lecture. Quarterly Journal of Experimental Psychology, 73(1), 1-19. doi:10.1177/1747021819886519

Bordignon, F. (2020). Self-correction of science: a comparative study of negative citations and postpublication peer review. Scientometrics. doi:10.1007/s11192-020-03536-z

Bornmann, L., \& Daniel, H. D. (2008). What do citation counts measure? A review of studies on citing behavior. Journal of Documentation, 64(1), 45-80. doi:10.1108/00220410810844150

Bouter, L. M., Tijdink, J., Axelsen, N., Martinson, B. C., \& ter Riet, G. (2016). Ranking major and minor research misbehaviors: results from a survey among participants of four World Conferences on Research Integrity. Research Integrity and Peer Review, 1(1), 17. doi:10.1186/s41073016-0024-5

Callaham, M., Wears, R. L., \& Weber, E. (2002). Journal Prestige, Publication Bias, and Other Characteristics Associated With Citation of Published Studies in Peer-Reviewed Journals. JAMA, 287(21), 2847-2850. doi:10.1001/jama.287.21.2847

Callaway, E. (2011). Report finds massive fraud at Dutch universities. Nature, 479(7371), 15-15. doi:10.1038/479015a

Camacho-Miñano, M.-d.-M., \& Núñez-Nickel, M. (2009). The multilayered nature of reference selection. Journal of the American Society for Information Science and Technology, 60(4), 754-777. doi:https://doi.org/10.1002/asi.21018

Chambers, C. (2017). The Seven Deadly Sins of Psychology. A Manifesto for Reforming the Culture of Scientific Pratice. Princeton, NJ: Princeton University Press.

Chubin, D. E., \& Moitra, S. D. (1975). Content Analysis of References: Adjunct or Alternative to Citation Counting? Social Studies of Science, 5(4), 423-441. doi:10.2307/284806

Coleman, L. (2021). Research in Crisis. Blueprint to Overhaul the Broken Knolwedge Factory. London \& New York, NY: Routledge, Taylor \& Francis Group.

Cozzens, S. E. (1989). What do citations count? The rhetoric-first model. Scientometrics, 15(5-6), 437447.

Cronin, B. (2005). A hundred million acts of whimsy? Current Science, 89(9), 1505-1509.

Cronin, B. (2016). The Incessant Chattering of Texts. In (pp. 13-19). Berlin, Boston: De Gruyter Saur. de Rijcke, S., Wouters, P. F., Rushforth, A. D., Franssen, T. P., \& Hammarfelt, B. (2015). Evaluation practices and effects of indicator use-a literature review. Research Evaluation, 25(2), 161169. doi:10.1093/reseval/rvv038

de Solla Price, D. J. (1963). Little science, big science. In. New York, NY.: Columbia University Press. 
De Solla Price , D. J. (1970). Citation measures of hard science, soft science, technology, and nonscience. In C. E. Nelson \& D. K. Pollock (Eds.), Communication among scientists and enginners (pp. 3-22). Lexington, MA: Health.

Edwards, M. A., \& Roy, S. (2016). Academic Research in the 21st Century: Maintaining Scientific Integrity in a Climate of Perverse Incentives and Hypercompetition. Environmental Engineering Science. doi:10.1089/ees.2016.0223

Fanelli, D. (2010). "Positive" Results Increase Down the Hierarchy of the Sciences. PLoS ONE, 5(3). doi:10.1371/journal.pone.0010068

Fiedler, K., \& Schwarz, N. (2016). Questionable Research Practices Revisited. Social Psychological and Personality Science, 7(1), 45-52. doi:10.1177/1948550615612150

Fiedler, K., \& Schwarz, N. (2016). Questionable Research Practices Revisited. 7(1), 45-52. doi:10.1177/1948550615612150

Garfield, E. (1955). Citation indexes to science: a new dimension in documentation through association of ideas. Science, 122(3159), 108-111.

Garfield, E. (1975). The Obliteration Phenomenon. . Current Contents(51/52), 5-7.

Gilbert, G. N. (1977). Referencing as Persuasion. Social Studies of Science, 7(1), 113-122. doi:10.1177/030631277700700112

Greenberg, S. A. (2009a). How citation distortions create unfounded authority: analysis of a citation network. BMJ, 339. doi:10.1136/bmj.b2680

Greenberg, S. A. (2009b). How citation distortions create unfounded authority: analysis of a citation network. 339, b2680. doi:10.1136/bmj.b2680 \%J BMJ

Gross, P. L., \& Gross, E. M. (1927). College libraries and chemical education. Science, 66(1713), 385389.

Hargens, L. L. (2000). Using the Literature: Reference Networks, Reference Contexts, and the Social Structure of Scholarship. American Sociological Review, 65(6), 846-865.

Hirsch, J. E. (2005). An Index to Quantify an Individual's Scientific Research Output. Proceedings of the National Academy of Sciences of the United States of America, 102(46), 16569-16572.

Hubbard, R. (2016). Corrupt Research. The Case for Reconceptualizing Empirical Management and Social Sciences. London, UK: Sage.

Ioannidis, J. A. (2005). Contradicted and initially stronger effects in highly cited clinical research. JAMA: The Journal of the American Medical Association, 294(2), 218-228. doi:10.1001/jama.294.2.218

loannidis, J. P. (2018). Massive citations to misleading methods and research tools: Matthew effect, quotation error and citation copying. European journal of epidemiology, 33(11), 1021-1023.

Jergas, H., \& Baethge, C. (2015). Quotation accuracy in medical journal articles-a systematic review and meta-analysis. PeerJ, 3, e1364.

John, L. K., Loewenstein, G., \& Prelec, D. (2012). Measuring the Prevalence of Questionable Research Practices With Incentives for Truth Telling. Psychological Science, 23(5), 524-532. doi:10.1177/0956797611430953

Johnson, B., \& Oppenheim, C. (2007). How socially connected are citers to those that they cite? Journal of Documentation.

Kaplan, N. (1965). The Norms of Citation Behavior: Prolegomena to the Footnote. American Documentation, 16(3), 179-184.

Kurtz, M. J., Eichhorn, G., Accomazzi, A., Grant, C., Demleitner, M., Murray, S. S., . . Elwell, B. (2005). The bibliometric properties of article readership information. Journal of the American Society for Information Science and Technology, 56(2), 111-128. doi:https://doi.org/10.1002/asi.20096

Latour, B. (1987). Science in action: How to follow scientists and engineers through society. Boston, MA: Harvard University Press.

Latour, B., \& Woolgar, S. (1986). Laboratory life. The construction of scientific facts (2nd ed.). Princeton, NJ: Princeton University Press. 
Law, J. (1986). The heterogeneity of texts. In M. Callon, J. Law, \& A. Rip (Eds.), Mapping the dynamics of science and technology (pp. 67-83). London, England: Macmillan.

Leng, G., \& Leng, R. I. (2020a). The Matter of Facts. Skepticism, Persuasion, and Evidence in Science. Cambrige, MA: MIT Press.

Leng, G., \& Leng, R. I. (2020b). The Matter of Facts: Skepticism, Persuasion, and Evidence in Science: Mit Press.

Leng, R. I. (2018). A network analysis of the propagation of evidence regarding the effectiveness of fat-controlled diets in the secondary prevention of coronary heart disease (CHD): Selective citation in reviews. Plos One, 13(5), e0197716. doi:10.1371/journal.pone.0197716

Liu, Z. (1997). Citation theories in the framework of international flow of information: New evidence with translation analysis. Journal of the American Society for Information Science, 48(1), 8087. doi:https://doi.org/10.1002/(SICI)1097-4571(199701)48:1<80::AID-ASI9>3.0.CO;2-Y

Luukkonen, T. (1997). Why has Latour's theory of citations been ignored by the bibliometric community? discussion of sociological interpretations of citation analysis. Scientometrics, 38(1), 27-37. doi:10.1007/BF02461121

MacRoberts, M. H., \& MacRoberts, B. R. (1984). The negational reference: Or the art of dissembling. Social Studies of Science, 14(1), 91-94.

MacRoberts, M. H., \& MacRoberts, B. R. (1989a). Citation analysis and the science policy arena. Trends in Biochemical Sciences, 14(1), 8-13. doi:https://doi.org/10.1016/09680004(89)90077-7

MacRoberts, M. H., \& MacRoberts, B. R. (1989b). Problems of citation analysis: A critical review. Journal of the American Society for Information Science, 40(5), 342-349. doi:10.1002/(SICI)1097-4571(198909)40:5<342::AID-ASI7>3.0.CO;2-U

MacRoberts, M. H., \& MacRoberts, B. R. (2010). Problems of citation analysis: A study of uncited and seldom-cited influences. Journal of the American Society for Information Science and Technology, 61(1), 1-12. doi:10.1002/asi.21228

MacRoberts, M. H., \& MacRoberts, B. R. (2017). The mismeasure of science: Citation analysis. Journal of the Association for Information Science and Technology, 69(3), 474-482. doi:10.1002/asi.23970

Martin, B. R. (2013). Whither research integrity? Plagiarism, self-plagiarism and coercive citation in an age of research assessment. Research Policy, 42(5), 1005-1014. doi:http://dx.doi.org/10.1016/j.respol.2013.03.011

Merton, R. (1979). Foreword by Eugene Garfield: Citation indexing - Its theory and application in science, technology, and humanities. In. Philadelphia, PA: ISI Press.

Merton, R. K. (1942). Note on science and democracy. Journal of Legal and Political Sociology, 1(1 and 2), 115-126.

Merton, R. K. (1968). MATTHEW EFFECT IN SCIENCE. Science, 159(3810), 56-\&. doi:10.1126/science.159.3810.56

Merton, R. K. (1968). Social Theory and Social Structure. New Yprk, NY: Columbia University Press.

Merton, R. K. (1988). The Matthew Effect in Science, II: Cumulative Advantage and the Symbolism of Intellectual Property. Isis, 79(4), 606-623.

Michael, H. M., \& Barbara, R. M. (1986). Quantitative Measures of Communication in Science: A Study of the Formal Level. Social Studies of Science, 16(1), 151-172. doi:10.1177/030631286016001008

Moravcsik, M. J., \& Murugesan, P. (1975). Some Results on the Function and Quality of Citations. Social Studies of Science, 5(1), 86-92.

Munafò, M. R., Nosek, B. A., Bishop, D. V. M., Button, K. S., Chambers, C. D., Percie du Sert, N., .. . Ioannidis, J. P. A. (2017). A manifesto for reproducible science. Nature Human Behaviour, 1, 0021. doi:10.1038/s41562-016-0021

Myers, G. (1985). The Social Construction of Two Biologists' Proposals. Written Communication, 2(3), 219-245. doi:10.1177/0741088385002003001 
Nicolaisen, J. (2007). Citation analysis. Annual Review of Information Science and Technology, 41(1), 609-641. doi:10.1002/aris.2007.1440410120

O'Boyle, E. H. J., Banks, G. C., \& Gonzalez-Mulé, E. (2017). The Chrysalis Effect. Journal of Management, 43(2), 376-399. doi:doi:10.1177/0149206314527133

Oberauer, K., \& Lewandowsky, S. (2019). Addressing the theory crisis in psychology. Psychonomic bulletin review, 26(5), 1596-1618.

OSF, O. S. C. (2015). Estimating the reproducibility of psychological science. Science, 349(6251). doi:10.1126/science.aac4716

Pettigrew, T. F. (2018). The Emergence of Contextual Social Psychology. Personality and Social Psychology Bulletin, 44(7), 963-971. doi:10.1177/0146167218756033

Popper, K. (1945). The Open Society and its enemies. Princeton, New Jersey: Princeton University Press.

Prinz, F., Schlange, T., \& Asadullah, K. (2011). Believe it or not: how much can we rely on published data on potential drug targets? Nat Rev Drug Discov, 10(9), 712-712.

Saltelli, A., \& Funtowicz, S. (2017). What is science's crisis really about? Futures, 91, 5-11. doi:https://doi.org/10.1016/j.futures.2017.05.010

Schneider, J. W. (2006). Concept symbols revisited: Naming clusters by parsing and filtering of noun phrases from citation contexts of concept symbols. Scientometrics, 68(3), 573-593. doi:10.1007/s11192-006-0131-z

Simkin, M., \& Roychowdhury, V. (2006). Do you sincerely want to be cited? Or: read before you cite. Significance, 3(4), 179-181. doi:10.1111/j.1740-9713.2006.00202.x

Small, H. (2004). On the shoulders of Robert Merton: Towards a normative theory of citation. Scientometrics Scientometrics, 60(1), 71-79. doi:10.1023/b:scie.0000027310.68393.bc

Small, H. G. (1978). Cited Documents as Concept Symbols. Social Studies of Science, 8(3), 327-340. doi:10.1177/030631277800800305

Stang, A., Jonas, S., \& Poole, C. J. E. j. o. e. (2018). Case study in major quotation errors: a critical commentary on the Newcastle-Ottawa scale. 33(11), 1025-1031.

Steneck, N. H. (2006). Fostering integrity in research: Definitions, current knowledge, and future directions. Science and Engineering Ethics, 12(1), 53-74. doi:10.1007/pl00022268

Stroebe, W. (2016). Are most published social psychological findings false? Journal of Experimental Social Psychology, 66, 134-144. doi:https://doi.org/10.1016/i.jesp.2015.09.017

Teplitskiy, M., Duede, E., Menietti, M., \& R., L. K. (2020, 31 Aug ). Status drives how we cite: Evidence from thousands of authors. https://arxiv.org/abs/2002.10033.

Trinquart, L., Johns, D. M., \& Galea, S. (2016). Why do we think we know what we know? A metaknowledge analysis of the salt controversy. International Journal of Epidemiology, 45(1), 251-260. doi:10.1093/ije/dyv184 \%J International Journal of Epidemiology

van Dalen, H. P., \& Henkens, K. n. (2005). Signals in science - On the importance of signaling in gaining attention in science. Scientometrics, 64(2), 209-233. doi:10.1007/s11192-005-0248-5

van der Steen, J. T., van den Bogert, C. A., van Soest-Poortvliet, M. C., Fazeli Farsani, S., Otten, R. H. J., ter Riet, G., \& Bouter, L. M. (2018). Determinants of selective reporting: A taxonomy based on content analysis of a random selection of the literature. PLOS ONE, 13(2), e0188247. doi:10.1371/journal.pone.0188247

Vazire, S. (2017). Quality Uncertainty Erodes Trust in Science. Collabra: Psychology, 3(1). doi:10.1525/collabra.74

Voos, H., \& Dagaev, K. S. (1976). Are All Citations Equal? Or, Did We Op. Cit. Your Idem? Journal of Academic Librarianship, 1(6), 19-21.

Wallace, M. L., Lariviere, V., \& Gingras, Y. (2012). A Small World of Citations? The Influence of Collaboration Networks on Citation Practices. PLOS ONE, 7(3). doi:10.1371/journal.pone.0033339

Wicherts, J. M. (2017). The Weak Spots in Contemporary Science (and How to Fix Them). Animals (Basel), 7(12). doi:10.3390/ani7120090 
Wilson, P. (2020). Academic Fraud: Solving the Crisis in Modern Academia. Exchanges: The Interdisciplinary Research Journal, 7(3), 14-44. doi:10.31273/eirj.v7i3.546

Zipf, G. K. (1949). Human behavior and the principle of least effort. Cambridge, MA: Addison-Wesley. 